\title{
A Hyperpolarization-Activated Inward Current in Heart Interneurons of the Medicinal Leech
}

\author{
James D. Angstadt and Ronald L. Calabrese \\ Emory University, Atlanta, Georgia 30322
}

Heart interneurons (HN cells) in isolated ganglia of the medicinal leech were voltage-clamped with single microelectrodes. Hyperpolarizing voltage steps elicited a slow inward current $\left(I_{h}\right)$, which underlies the characteristic depolarizing response of $\mathrm{HN}$ cells to injection of prolonged hyperpolarizing current pulses (Arbas and Calabrese, 1987a). The conductance underlying $I_{h}$ begins to activate near $-50 \mathrm{mV}$ and is fully activated between -70 and $-80 \mathrm{mV}$. The activation kinetics of $I_{n}$ are slow and voltage dependent. The activation time constant $\left(\tau_{h}\right)$ ranges from approximately $2 \mathrm{sec}$ at -60 $\mathrm{mV}$ to near $700 \mathrm{msec}$ at $-100 \mathrm{mV}$. $I_{h}$ persists in low $\mathrm{Ca}^{2}$ (0.1 $\mathrm{mm}$ ), $5 \mathrm{mM} \mathrm{Mn}^{2+}$ saline and exhibits a reversal potential of $-21 \pm 5 \mathrm{mV}$. The reversal potential is shifted by altering $\left[\mathrm{Na}^{+}\right]_{0}$ or $\left[\mathrm{K}^{+}\right]_{0}$ but is unaffected by changes in $\left[\mathrm{Cl}^{-}\right]_{0} I_{h}$ is blocked by extracellular $\mathrm{Cs}^{+}$(1-5 mm) but not $\mathrm{Ba}^{2+}(5 \mathrm{~mm})$ or TEA (25 mM). Low concentrations of $\mathrm{Cs}^{+}(100-200 \mu \mathrm{M})$ cause a partial block that exhibits strong voltage dependence. Temperature changes were also shown to affect $I_{h}$. Both the rate of activation and the steady-state amplitude of $I_{h}$ are enhanced by temperature increases.

HN cells are interconnected by inhibitory chemical synapses, and their normal electrical activity consists of bursts of action potentials separated by periods of inhibition. During the inhibitory phase of rhythmic bursting activity, HN cells hyperpolarize to a voltage range where $I_{h}$ is activated. Block of $I_{h}$ with extracellular $\mathrm{Cs}^{+}(4 \mathrm{~mm}$ ) disrupted the normal bursting activity of HN cells. These results are consistent with the hypothesis that $I_{h}$ contributes to escape from inhibitory inputs during normal bursting activity.

Circulation in the medicinal leech is generated by rhythmic constrictions of 2 lateral blood vessels called heart tubes. Beat timing and coordination of the heart tube contractions are controlled by a central pattern generator consisting of 7 bilateral pairs of heart interneurons (HN cells) located in segmental ganglia 1-7 (Thompson and Stent, 1976; Calabrese, 1977; Peterson and Calabrese, 1982). The HN cells are interconnected by inhibitory chemical synapses and their normal electrical activity consists of bursts of action potentials separated by periods of

\footnotetext{
Received Nov. 7, 1988; revised Jan. 16, 1989; accepted Jan. 18, 1989.

We wish to thank Dr. P. R. Lennard for generously providing equipment needed for some of the experiments and Dr. K. J. Thompson and Dr. M. V. S. Siegler for valuable discussions during the preparation of the manuscript. We also thank Dr. H. C. Hartzell for his comments on the manuscript. This work was supported by NIH Grant NS24072, NRSA Fellowship NS08089, and a Grass Foundation Fellowship to J.D.A.

Correspondence should be addressed to James D. Angstadt, Biology Department, 1555 Pierce Drive, Emory University, Atlanta, GA 30322.

Copyright (c) 1989 Society for Neuroscience $0270-6474 / 89 / 082846-12 \$ 02.00 / 0$
}

inhibition. The generation of rhythmic activity in $\mathrm{HN}$ cells appears to derive from at least 2 major factors, synaptic inhibition and intrinsic membrane properties. Peterson (1983) showed that synaptic inhibition between $\mathrm{HN}$ cells was primarily responsible for burst termination in each cycle but that burst initiation appeared to depend on intrinsic properties of the HN cells. Recent studies suggest that activation of voltage-sensitive conductances may provide a mechanism for escape from inhibition and subsequent burst generation. Arbas and Calabrese (1987a) showed that during injection of a prolonged hyperpolarizing current pulse into HN cells, an initial peak response was followed by a slow depolarizing "sag" of the membrane potential. The sag was suppressed in reduced $\mathrm{Na}^{+}$salines but persisted in the presence of $10 \mathrm{mM} \mathrm{Co}{ }^{2+}$. The sag voltage response was hypothesized to provide a mechanism for active escape from inhibitory inputs during oscillatory activity.

We have begun to investigate the ionic currents of $\mathrm{HN}$ cells directly using the switching single-electrode voltage-clamp technique. In the present study we report on a hyperpolarizationactivated inward current $\left(I_{h}\right)$ that underlies the sag voltage response. During normal bursting activity, $\mathrm{HN}$ cells are hyperpolarized to membrane potentials where the conductance is strongly activated. Blocking $I_{h}$ disrupts normal bursting activity in HN cell pairs, suggesting that this current may play an important role in the generation of oscillatory activity in these interneurons.

\section{Materials and Methods}

Leeches (Hirudo medicinalis) were obtained from European suppliers and maintained in artificial pond water at $15^{\circ} \mathrm{C}$. Animals were anesthetized in cold saline and selected segmental ganglia removed for study. $\mathrm{HN}$ cells occur as bilateral pairs in segmental ganglia $1-7$ and are indexed according to ganglion and side [e.g., $\mathrm{HN}(\mathrm{R}, 1) \ldots \mathrm{HN}(\mathrm{L}, 7)]$. In this study, we examined HN cells in G3, G4, and G7. HN cells in G1-G2 and $\mathrm{G} 5-\mathrm{G} 6$ were not used for technical reasons. HN cells in $\mathrm{G} 3$ and $\mathrm{G} 4$ are connected with reciprocal inhibitory synapses that are critical for generating rhythmic bursting (Peterson, 1983); in contrast, HN cells in G7 are not connected. No obvious differences in the hyperpolarization activated inward current $\left(I_{h}\right)$ were seen between HN cells in different ganglia.

Individual ganglia were pinned ventral side up in petri dishes lined with Sylgard resin (bath volume, $0.5 \mathrm{ml}$ ). The connective tissue sheath overlying the nerve cell bodies was removed by dissection immediately prior to the experiment. Ganglia were continuously superfused $(1.5 \mathrm{ml} /$ min) with normal leech saline (Nicholls and Baylor, 1968) containing (in $\mathrm{mm}$ ): $\mathrm{NaCl}, 115 ; \mathrm{KCl}, 4 ; \mathrm{CaCl}_{2}, 1.8$; glucose, 10; Tris buffer, 10 , adjusted to $\mathrm{pH}$ 7.4. In many experiments a modified saline containing reduced $\mathrm{CaCl}_{2}(0.1 \mathrm{~mm})$ and $5 \mathrm{mM} \mathrm{MnCl}_{2}$ was used to block Ca currents. The normal osmolarity and $\mathrm{Cl}^{-}$concentration were maintained by reducing $\mathrm{NaCl}$ to $108.5 \mathrm{~mm}$ and increasing glucose to $13.3 \mathrm{~mm}$. In reduced $\mathrm{Na}^{+}$salines, $\mathrm{Na}^{+}$was replaced with an equimolar concentration of Tris or $N$-methyl-D-glucamine. $\mathrm{CsCl}(0.1-5 \mathrm{~mm}), \mathrm{RbCl}(1 \mathrm{~mm}), \mathrm{BaCl}_{2}(5$ $\mathrm{mM})$, and TEA-Cl (25 mM) were added without compensation. Exper- 


\section{$H N(R, 4)$}

A. CURRENT CLAMP
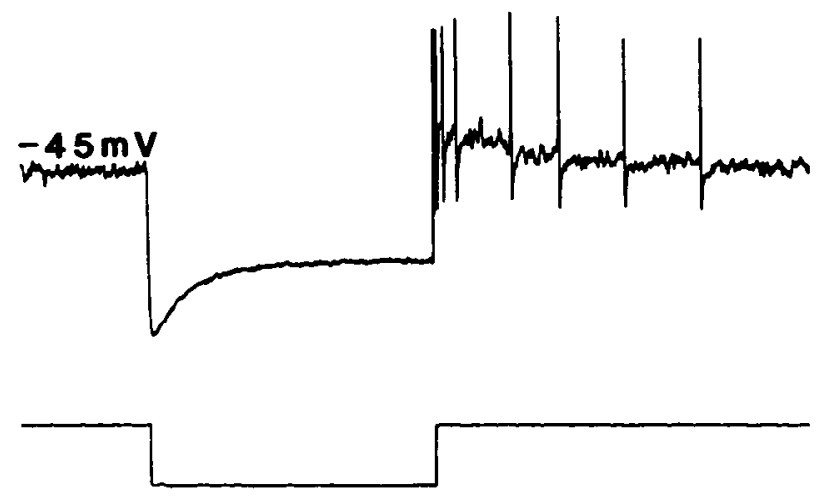

$30 \mathrm{mV}$

$1.5 \mathrm{nA}$

\section{$3 \sec$}

B. VOLTAGE CLAMP
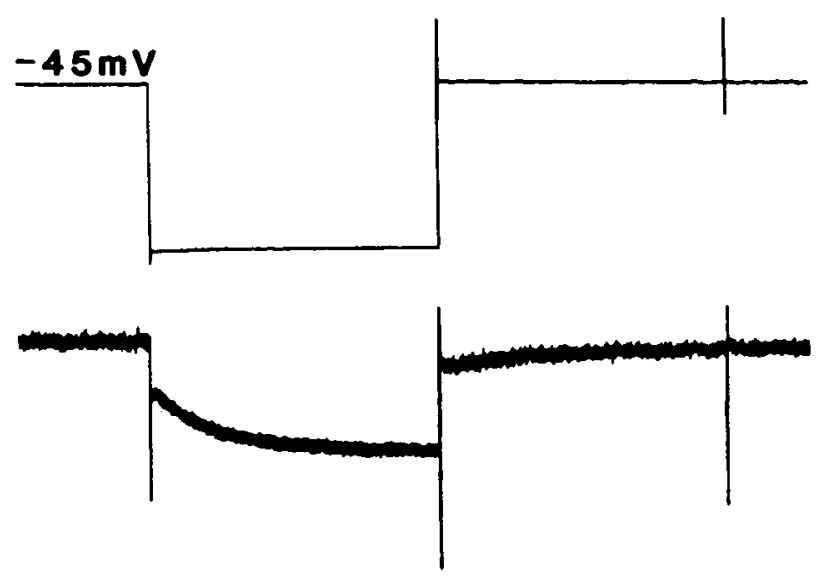

Figure 1. Comparison of responses to membrane potential hyperpolarization of an $\mathrm{HN}(\mathrm{R}, 4)$ cell in current and voltage-clamp modes. The preparation was bathed in $5 \mathrm{mM} \mathrm{Mn}{ }^{2+}$ saline throughout. $A$, Membrane potential response to injection of a prolonged hyperpolarizing current pulse in DCC. After reaching an initial peak hyperpolarization, the membrane potential slowly depolarizes despite the maintained current injection (sag voltage response). $B$, Same cell in SEVC mode. From a holding potential of $-45 \mathrm{mV}$, the membrane potential is stepped to $-80 \mathrm{mV}$ for 6 sec. A slowly developing inward current, $I_{h}$, is activated by the voltage step. An inward tail current at the offset of the voltage step corresponds to the slow depolarization underlying the spikes observed in DCC. Note that the clamp circuit fails to control the fast Na-dependent action potentials occurring spontaneously and at the offset of the hyperpolarizing voltage step. However, voltage control is maintained during activation of $I_{h}$.

iments were performed at room temperature $\left(23-27^{\circ} \mathrm{C}\right)$ except where noted.

HN cells were penetrated with borosilicate microelectrodes $(1 \mathrm{~mm}$ o.d., $0.75 \mathrm{~mm}$ i.d.) filled with $3 \mathrm{M} \mathrm{KCl}$ or $4 \mathrm{M} \mathrm{KAc}$ with resistances of $30-40$ or $50-80 \mathrm{M} \Omega$, respectively. HN cells were identified by their posterior-lateral position on the ventral side of the ganglion and by their characteristic bursting behavior. An Axoclamp-2A microelectrode voltage clamp (Axon Instruments) was used in either discontinuous current clamp (DCC) or switching single-electrode voltage-clamp (SEVC) mode. In both DCC and SEVC, the voltage input to the sample and hold circuit during each cycle was continuously monitored with a second oscilloscope to ensure complete settling between current injection cycles. The relatively high resistance of the microelectrodes, which was required to prevent damage to the $\mathrm{HN}$ cell bodies ( $\sim 30 \mu \mathrm{m}$ diameter), limited the sampling frequency and feedback gain of the system. Sample rates typically ranged from 1.5 to $3 \mathrm{kHz}$ and clamp gain from 1 to $2.5 \mathrm{nA} / \mathrm{V}$. It was impossible, for example, to control the large and rapidly activating currents associated with action potentials. Fortunately, because of its relatively small amplitude (a few $\mathrm{nA})$ and slow activation $\left(\tau_{h}=700\right.$ $2500 \mathrm{msec}$ ), it was possible to maintain the HN cell soma under good voltage control during activation of $I_{h}$. It is more difficult to assess the quality of space clamp in the rather extensive dendritic tree of the HN cells. The input resistance of $H N$ cells is approximately $50 \mathrm{M} \Omega$, and hyperpolarizing voltage steps readily suppress spontaneous action potentials and reverse $\mathrm{Cl}^{-}$-mediated IPSPs, which are known to arise at the distal tips of the HN cell dendrites (Tolbert and Calabrese, 1985). This observation suggests that the HN cell may be fairly compact electrically.

Data were recorded on a VHS video cassette recorder modified for FM recording (Vetter, model 240) for later playback on paper chart recorders (Gould). In addition, data were routinely digitized, stored, and analyzed on a personal computer using pClamp software (Axon Instruments). Digitized data were displayed on a Hewlett-Packard plotter (model 7470A). Current records were sometimes filtered using a digital smoothing option provided with the pClamp software. In all cases, the filter was adjusted so that ionic current trajectories were unaffected by the smoothing process.

In some experiments, a test saline was cooled or heated in a temperature-controlled water jacket and delivered to the preparation via the same gravity feed system as the room temperature saline. The temperature of the superfusate was continuously monitored with a thermistor placed in the recording chamber adjacent to the ganglion.

\section{Results}

A comparison of the sag voltage response of an $\mathrm{HN}$ cell in current clamp to the net ionic current obtained in response to a similar hyperpolarization delivered in voltage clamp is shown in Figure 1. The preparation was bathed in $5 \mathrm{mM} \mathrm{Mn}^{2+}$ saline to eliminate $\mathrm{Ca}$-dependent plateau potentials and chemical synaptic interactions with the contralateral $\mathrm{HN}$ cell. The saline also suppressed spontaneous action potentials and bursting seen in normal saline (cf. Fig. $11 A$ ). In current clamp (Fig. $1 A$ ), a prolonged hyperpolarizing current pulse delivered to an $\operatorname{HN}(\mathrm{R}, 4)$ cell causes a rapid hyperpolarization that is followed by a slowerdeveloping depolarization (the sag voltage response) that persists in the face of maintained hyperpolarizing current. Several spikes associated with a slow depolarization occur at the offset of the current pulse. Figure $1 B$ shows the same cell in voltage clamp. The membrane potential was stepped from a holding level of $-45 \mathrm{mV}$ to a command potential of $-80 \mathrm{mV}$ (corresponding to the peak hyperpolarization observed in current clamp). Following the initial surge of capacitative and leak currents, a slow inward current that approaches a steady plateau near the end of the $6 \mathrm{sec}$ voltage step is activated. It is this 

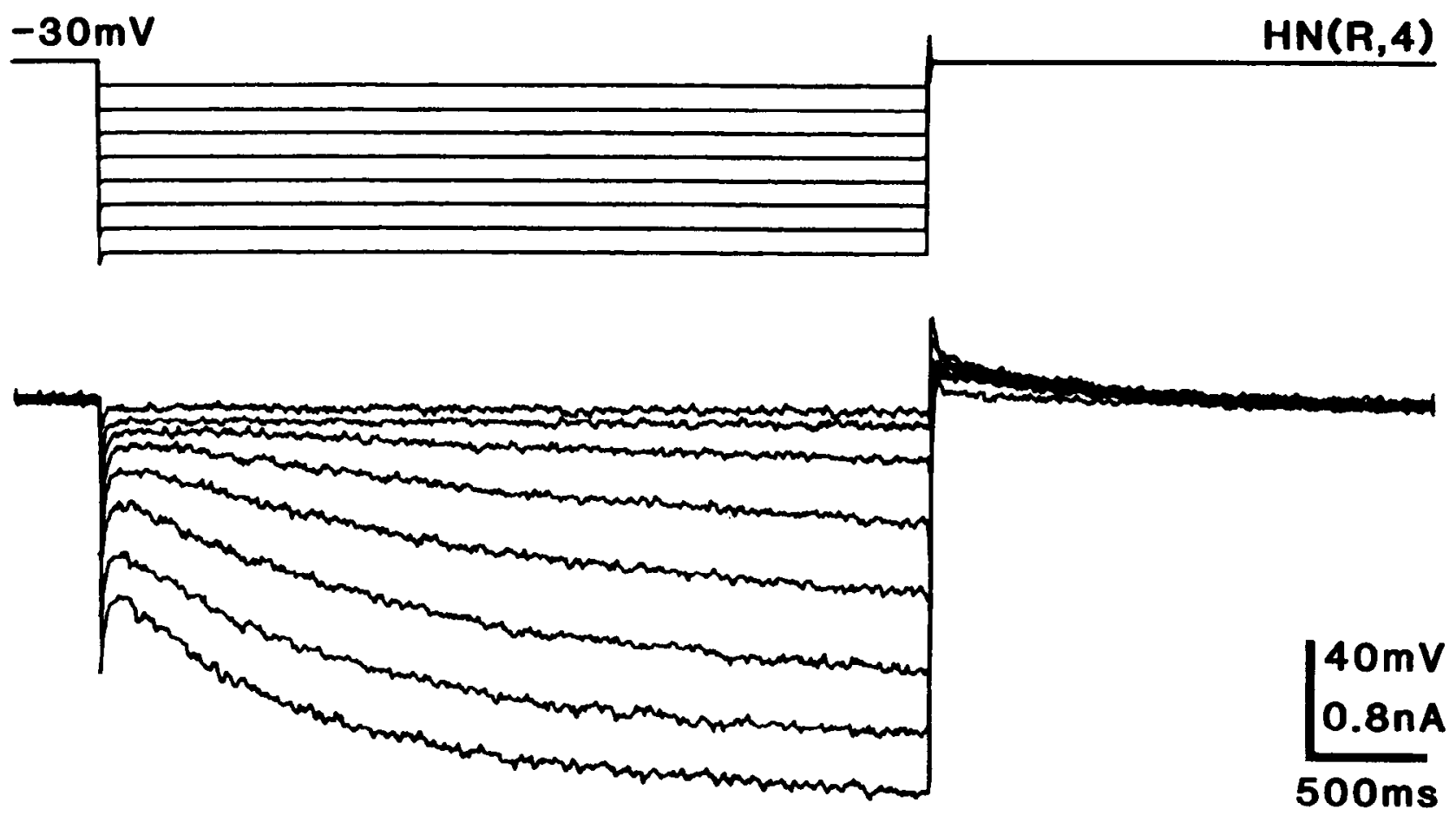

Figure 2. Inward currents generated in an $\mathrm{HN}(\mathrm{R}, 4)$ cell by hyperpolarizing voltage steps from a holding potential of $-30 \mathrm{mV}$. Preparation bathed in $\mathrm{Mn}^{2+}$ saline. The small outward tail currents after the voltage steps represent a mixture of inward $I_{h}$ tail currents and rapid voltage-gated outward currents with thresholds near $-30 \mathrm{mV}$.

inward current that underlies the sag voltage response observed in current clamp. Due to its activation by membrane hyperpolarization and its similarities with other hyperpolarizationactivated inward currents (Mayer and Westbrook, 1983; Bader and Bertrand, 1984), this current will be referred to as $I_{h}$.

\section{Voltage dependence of $\mathrm{I}_{\mathrm{h}}$ activation}

Figure $2 A$ illustrates a family of inward currents produced by hyperpolarizing voltage steps in an $\mathrm{HN}$ cell bathed in $\mathrm{Mn}^{2+}$ saline. In this experiment, the $\mathrm{HN}$ cell was clamped at a holding potential of $-30 \mathrm{mV}$ and stepped in $-10 \mathrm{mV}$ increments to more hyperpolarized levels. In this particular cell, voltage steps to -40 and $-50 \mathrm{mV}$ elicited little or no time-dependent inward current. However, during the third step to $-60 \mathrm{mV}$ a slowly developing inward current was activated. Note the delay to current onset which is most apparent in this and the following 2 traces. Subsequent steps produced increasingly larger and more rapidly activating inward currents. In addition, the delay to current onset decreased markedly with larger hyperpolarizations. The inward currents are characterized by slow activation and persistence. $I_{h}$ shows no signs of inactivation during maintained hyperpolarization up to $20 \mathrm{sec}$ in duration (data not shown) and requires approximately $5 \mathrm{sec}$ to reach steady state (Fig. 1B).

Figure 3 illustrates the methods used to determine the voltage dependence of the steady-state conductance, $g_{h, \infty}$. Figure $3 A$ shows current records obtained in response to prolonged hyperpolarizing voltage steps in an $H N(R, 3)$ cell. Long-duration voltage steps $(6 \mathrm{sec})$ were used to ensure full activation of the conductance. From the holding level of $-35 \mathrm{mV}$, the membrane potential was stepped in $-5 \mathrm{mV}$ increments to potentials between -40 and $-85 \mathrm{mV}$ (steps to 5 different levels are illustrated). An inward tail current was recorded at $-50 \mathrm{mV}$ im- mediately following each voltage step. Tail currents were measured at $-50 \mathrm{mV}$ to prevent any possible contamination from voltage-sensitive outward currents.

The steady-state conductance at each voltage was determined by 2 different methods. In the first method (Fig. $3 B$, filled circles), conductance was calculated using the following equation,

$$
g_{h, \infty}=I_{h, \infty}\left(V_{m}-E_{h}\right)
$$

where $V_{m}$ indicates the command potential and $E_{h}$ the reversal potential of $-21 \mathrm{mV}$ (see Fig. $5 A$ ). $l_{h, \infty}$ represents only the slow, time-dependent inward current activated during the step and was measured as illustrated in the inset of Figure $3 B$. In the second method (Fig. 3B, open circles), steady-state conductance was estimated from the amplitude of the tail currents measured at $-50 \mathrm{mV}$ after normalizing to the maximum tail current obtained. Instantaneous currents, measured as the response to 200 msec hyperpolarizing voltage steps from -35 to $-50 \mathrm{mV}$, were subtracted from the total tail current at $-50 \mathrm{mV}$ to yield the fraction of tail current due to $I_{h}$ (labeled $I$ in Fig. $3 B$, inset). Both methods yielded comparable results and indicate that the conductance underlying $I_{h}$ begins to activate near $-50 \mathrm{mV}$ and increases to a maximum between -70 and $-80 \mathrm{mV}$. The results illustrated for this $\mathrm{HN}$ cell are representative of all the $\mathrm{HN}$ cells examined $(n=20)$.

\section{Kinetics of $\mathrm{I}_{\mathrm{h}}$ activation}

The main features of $I_{h}$ activation are apparent in the current traces illustrated in Figure 2. As in other systems (Hestrin, 1987), $I_{h}$ activation appears to consist of 2 components. The first component, which was defined as "instantaneous," occurs within the first $50 \mathrm{msec}$ and overlaps with the capacitative transient. The second component develops over several seconds and will be referred to as the time-dependent current. Treatments that 
A.
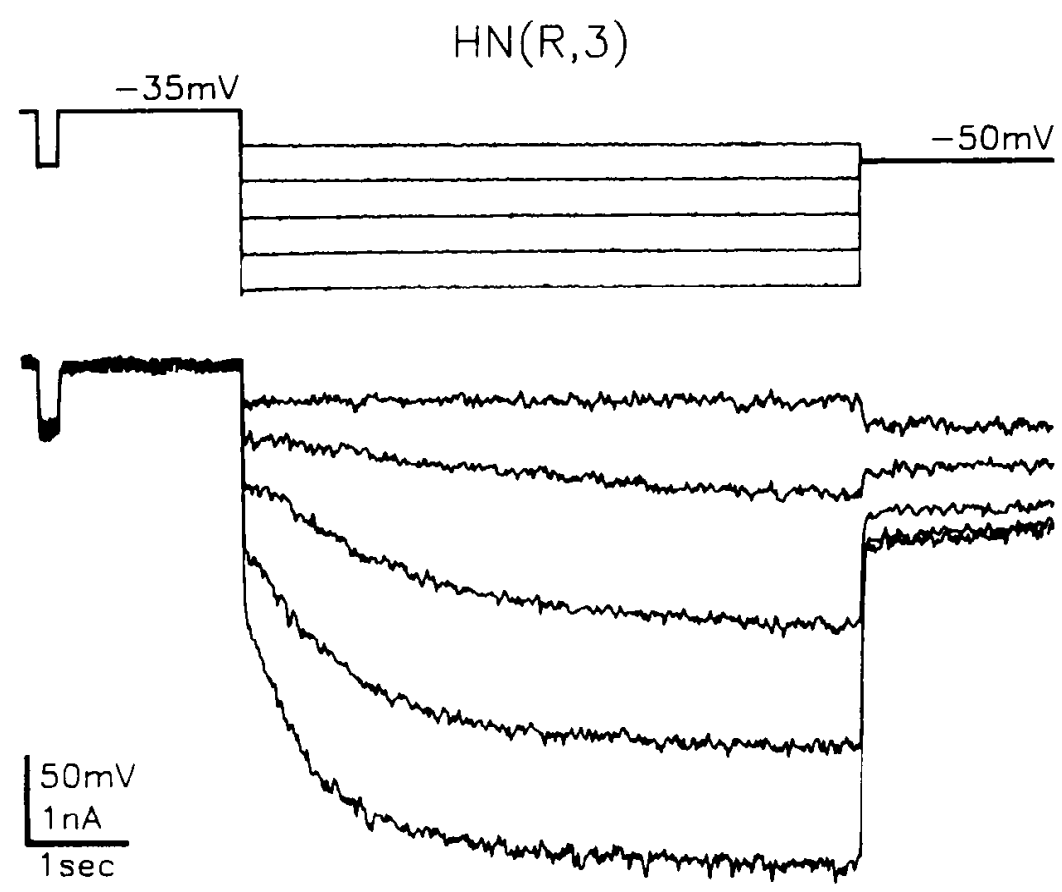

B.

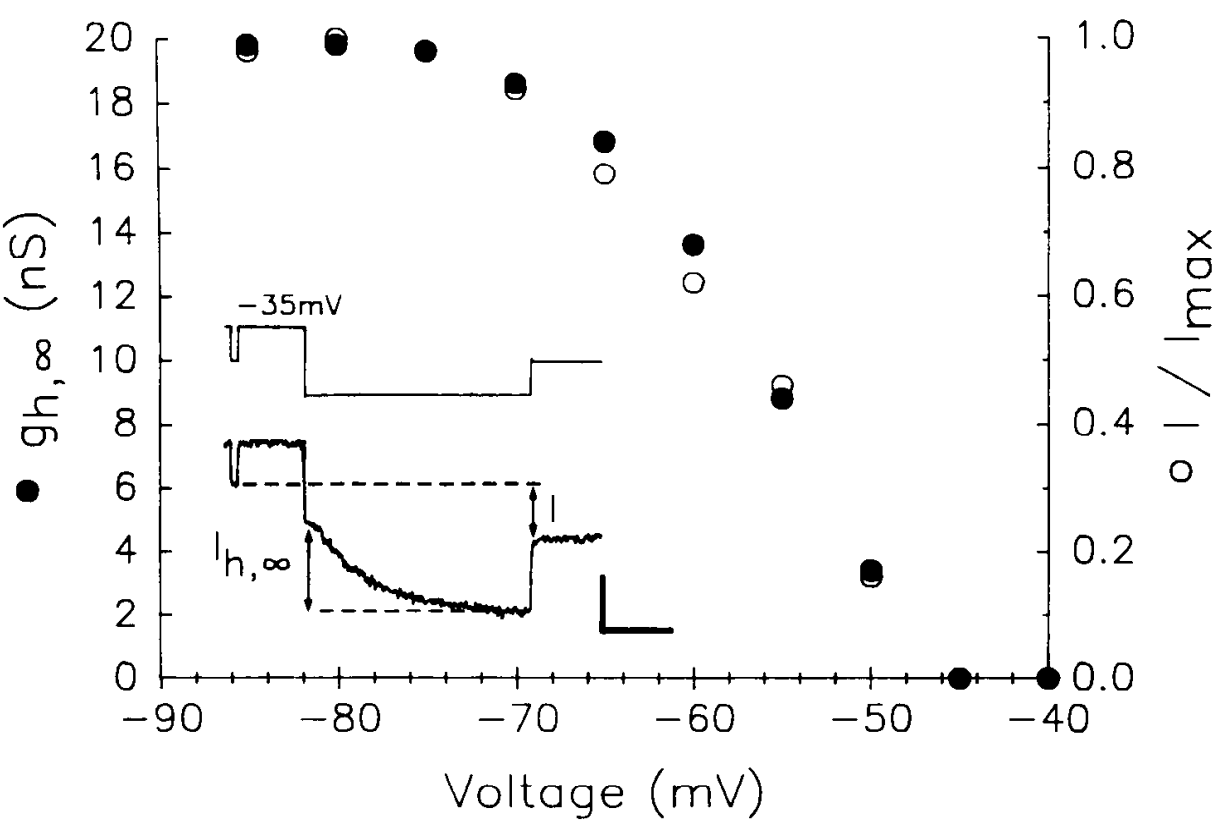

Figure 3. A, Examples of inward currents generated by hyperpolarizing voltage steps in an $H N(R, 3)$ cell in $\mathbf{M n}^{2+}$ saline. A series of prolonged voltage steps from a holding potential of -35 $\mathrm{mV}$ to more hyperpolarized membrane potentials were used to fully activate the conductance underlying $I_{h}$. Each episode consisted of a brief voltage pulse to $-50 \mathrm{mV}$ followed by a 6 sec hyperpolarizing voltage step of variable amplitude. After each voltage step, the membrane potential was returned to $-50 \mathrm{mV}$ for measurement of inward tail current. Prolonged voltage steps to $-45,-55,-65,-75$, and $-85 \mathrm{mV}$ are illustrated. $B$, Plots of the steady-state conductance determined by 2 different methods in the same cell as in $A$ are illustrated. Filled circles show the steady-state conductance obtained from measurements of the steady-state timedependent inward current recorded at each potential $\left(I_{h, \infty}\right)$. Open circles show the steady-state conductance estimated from the amplitude of tail currents measured at $-50 \mathrm{mV}$. Inset, Voltage and current records for the step to -65 $\mathrm{mV}$ and the methods used to measure $I_{h, \infty}$ and the $I_{h}$ tail current $(I)$. Scale bar: $25 \mathrm{mV}, 0.5 \mathrm{nA}$, and $2 \mathrm{sec}$. Methods used to calculate steady-state conductance from the above currents are described in the text. suppress the time-dependent current, i.e., Na-free saline (see Fig. 6) or extracellular $\mathrm{Cs}^{+}$(see Fig. 8), also decrease or eliminate the "instantaneous" component. However, some nonlinearity of the "instantaneous" current can persist under these conditions. It is not yet clear whether these residual currents are due to $I_{h}$ itself (e.g., incomplete block) or to contamination from other ionic currents. In any event, our analysis was restricted to the slow, time-dependent fraction of the current, and the term $I_{h}$ will refer only to this component.

After an initial delay, the rate of activation of $I_{h}$ follows a single-exponential time course and exhibits strong voltagc dcpendence. Figure $4 A$ illustrates the mean activation time con- stants $\left(\tau_{h}\right)$ as a function of membrane potential. At $-60 \mathrm{mV}, \tau_{h}$ is approximately $2.0 \mathrm{sec}$ but decreases to a mean value of 730 msec for steps to $-100 \mathrm{mV}$. The time constants obtained varied considerably among different preparations, but within any one neuron, the rate of activation was invariably slowest near the activation threshold and increased markedly with larger hyperpolarizations. Similarly, the delay to current onset was greatest near the activation threshold $(\sim 1 \mathrm{sec})$ and decreased (in some cases merging with the capacity transient) with larger hyperpolarizing steps. Figure $4 B$ illustrates the delay to $I_{h}$ onset for 2 representative $\mathrm{HN}$ cells.

Because of interference from outward potassium currents pos- 

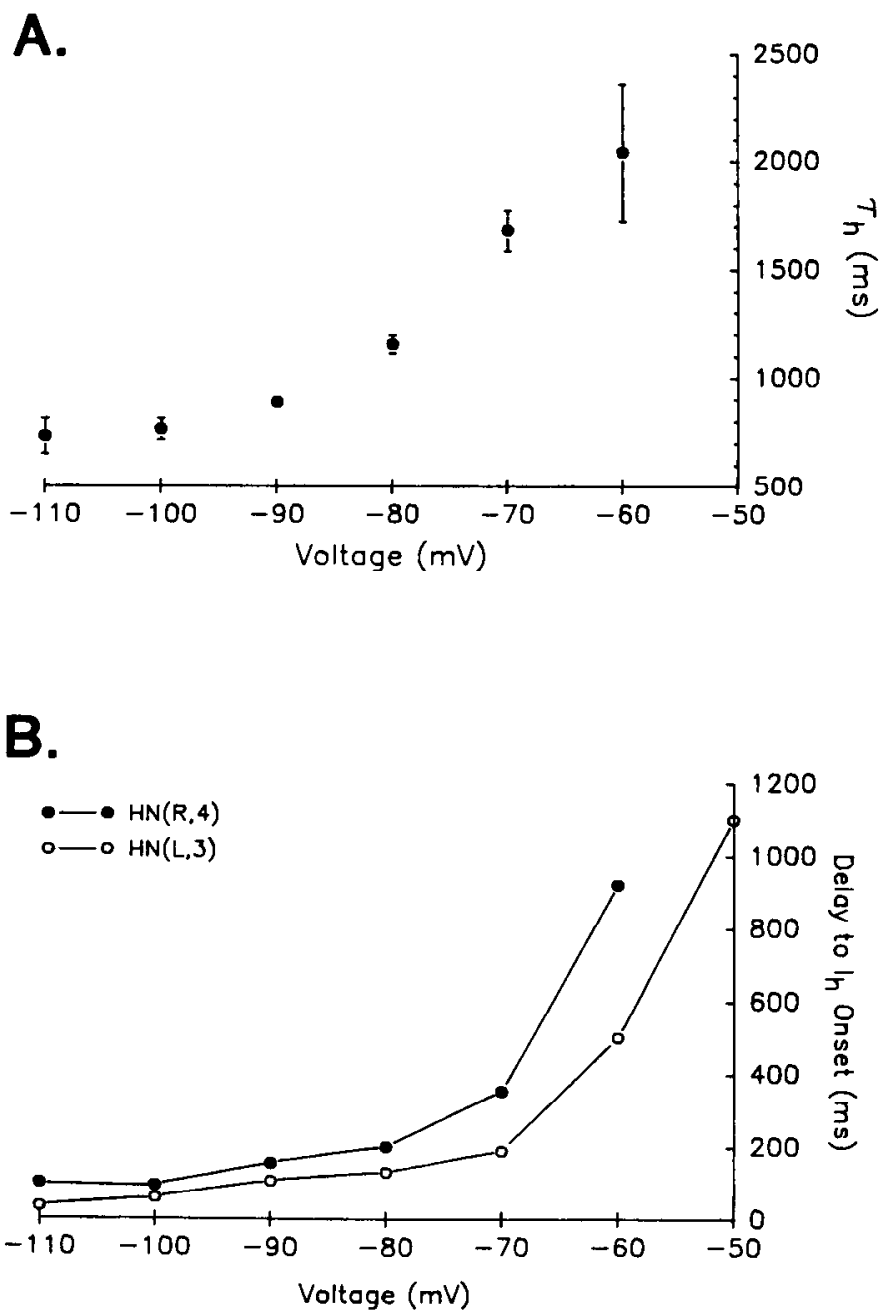

Figure 4. Kinetics of $I_{h}$ activation in $\mathrm{Mn}^{2+}$ saline. A, Graph of $I_{h}$ activation time constants $\left(\tau_{h}\right)$ versus membrane potential. Each point represents the mean $\pm \mathrm{SE}$ for at least $17 \mathrm{HN}$ cells, except at $-60 \mathrm{mV}$, which represents 7 cells (fewer points were available because of the small amplitude of $I_{h}$ near threshold, which often prevents an accurate measure of $\tau_{h}$ ). B. Graph of delay to onset of time-dependent current for $2 \mathrm{HN}$ cells. The delay is substantial (several hundred milliseconds to seconds) in the voltage range reached by the cell during inhibition in normal saline $(-50$ to $-70 \mathrm{mV})$.

itive to $-30 \mathrm{mV}$ and the relatively small amplitude of $I_{h}$ tail currents negative to the reversal potential, the kinetics of $I_{h}$ deactivation were not examined.

\section{Ionic dependence of $\mathrm{I}_{\mathrm{h}}$}

The $I_{h}$ reversal potential $\left(E_{h}\right)$ was determined as shown in Figure $5 A 1$. The conductance was maximally activated by stepping to a command potential of -90 to $-100 \mathrm{mV}$ for $5 \mathrm{sec}$. The membrane potential was subsequently stepped to a test potential for approximately $2 \mathrm{sec}$ and then returned to the original holding potential. Finally, "instantaneous" and leak currents were measured with a brief ( $200-250 \mathrm{msec})$ voltage pulse to the same test potential. The instantaneous current was subtracted from the current flowing at the test potential to yield the maximally activated, time-dependent current, $I_{\mathrm{h}^{\prime}}$ (Fig. $5 A I$, inset). This sequence was repeated for a variety of test potentials between -90 and $-35 \mathrm{mV}$. Test potentials positive to $-35 \mathrm{mV}$ were not used to prevent contamination by voltage-gated outward currents. $I_{\mathrm{h}}$, was plotted as a function of membrane potential and the data points fit by linear regression. The regression line was extrapolated to zero current to yield the estimated reversal potential. Based on this method, $I_{h}$ exhibits a reversal potential of $-21 \pm \mathrm{SD}$ of $5.1 \mathrm{mV}(n=23)$ in $5 \mathrm{mM} \mathrm{Mn}^{2+}$ saline.

The value of the $I_{h}$ reversal potential suggested that 2 or more ion species were contributing to the current. Changes in extracellular $\mathrm{Na}^{+}$or $\mathrm{K}^{+}$produced consistent shifts of $E_{h}$ along the voltage axis, suggesting that these ions contribute to the current (see below). However, reductions of extracellular $\mathrm{Cl}^{-}$to $50 \%$ normal (61 mM Cl- replaced with isethionate) had no effect on the amplitude or reversal potential of $I_{h}$. The cffects of altering extracellular $\mathrm{Ca}^{2+}$ were not investigated since we performed the experiments in low $\mathrm{Ca}^{2+}, \mathrm{Mn}^{2+}$ saline in order to block $I_{\mathrm{Ca}}$ as well as to raise threshold sufficiently to avoid contamination from Na-dependent action potentials; $50 \mu \mathrm{M}$ TTX fails to block action potentials in $\mathrm{HN}$ cells (data not shown).

Reducing $\left[\mathrm{Na}^{+}\right]_{0}$ would be expected to reduce the driving force for $\mathrm{Na}$ into the cell and, if $\mathrm{Na}^{+}$ions contribute to $I_{h}$, lead to a negative shift of $E_{h}$. Figure $5 A 1$ illustrates the negative shifts of $E_{h}$ obtained in one preparation with $75 \%(86.2 \mathrm{mM}), 50 \%(57.5$ $\mathrm{mM})$, and $25 \%(28.8 \mathrm{mM})$ normal $\left[\mathrm{Na}^{+}\right]_{0}$. Figure $5 A 2$ shows a plot of $E_{h}$ as a function of [ $\left.\mathrm{Na}^{+}\right]_{0}$ pooled from a number of preparations. The plot shows that $E_{h}$ varies linearly with the log of $\left[\mathrm{Na}^{+}\right]_{0}$ over the range of concentrations tested.

Reductions of $\left[\mathrm{Na}^{+}\right]_{0}$ to 75 or $50 \%$ of normal produce parallel shifts of the $I / V$ curves along the voltage axis. However, reducing $\left[\mathrm{Na}^{+}\right]_{o}$ to $25 \%$ normal causes a decrease in the slope of the $I / V$ curve (Fig. $5 A I$ ). When $100 \%$ of the $\mathrm{Na}^{+}$is removed (Na-free saline), $I_{h}$ is eliminated (Fig. 6). This result is consistent with the previously reported block of the sag voltage response in Na-free saline (Arbas and Calabrese, 1987a). The suppression of $I_{h}$ in Na-free saline is highly reproducible and occurs when $\mathrm{Na}^{+}$is replaced with Tris $(n=12)$ or with $N$-methyl-D-glucamine $(n=7)$. On the other hand, some fraction of $I_{h}$ does persist in high $\mathrm{K}^{+}$, Na-free saline $(n=7)$. Figure 7 shows a graph comparing the time-dependent inward current in control and Nafree, $25 \mathrm{~mm} \mathrm{~K}^{+}$salines. Although reduced compared with control currents, some inward current clearly persists under these conditions.

Changes in extracellular $\mathrm{K}^{+}$also shift the reversal potential of $I_{h}$. Figure $5 B l$ shows an experiment in which the normal $\left[\mathrm{K}^{+}\right]_{\mathrm{o}}$ of $4 \mathrm{~mm}$ was increased to 10 or $20 \mathrm{~mm}$. In these experiments $\left[\mathrm{Na}^{+}\right]_{\mathrm{o}}$ was maintained at $50 \%$ normal $(57.5 \mathrm{~mm})$. The reduced $\left[\mathrm{Na}^{+}\right]_{0}$ shifted $E_{h}$ to more hyperpolarized potentials and allowed the positive shifts produced by increased $\left[\mathrm{K}^{+}\right]_{\mathrm{o}}$ to occur in a voltage range below the activation threshold for other voltage-sensitive outward currents. Thus, in these experiments $E_{h}$ in control saline $\left(\left[\mathrm{K}^{+}\right]_{0}=4 \mathrm{mM}\right)$ was approximately $-40 \mathrm{mV}$ (Fig. 5B2). Increasing $\left[\mathrm{K}^{+}\right]_{\mathrm{o}}$, which would be expected to decrease the driving force on $\mathrm{K}^{+}$movement out of the cell, resulted in positive shifts of $E_{h}$. Conversely, reduction of $\left[\mathrm{K}^{+}\right]_{0}$ to $2 \mathrm{~mm}$ produced a small negative shift of $E_{h}$ (Fig. 5B2).

Unlike the effects of $\mathrm{Na}$ substitution, even small changes in $\left[\mathrm{K}^{+}\right]_{\text {o }}$ resulted in obvious changes in the slope of the current versus voltage plots (Fig. $5 B 1$ ). Such slope changes are consistent with the effects of altering extracellular $\mathrm{K}^{+}$on similar currents in other systems (DiFrancesco, 1981; Mayer and Westbrook, 1983; Bader and Bertrand, 1984) and have led to the suggestion that $\mathrm{K}^{+}$ions interact with the channels to influence their gating characteristics (DiFrancesco, 1982). 

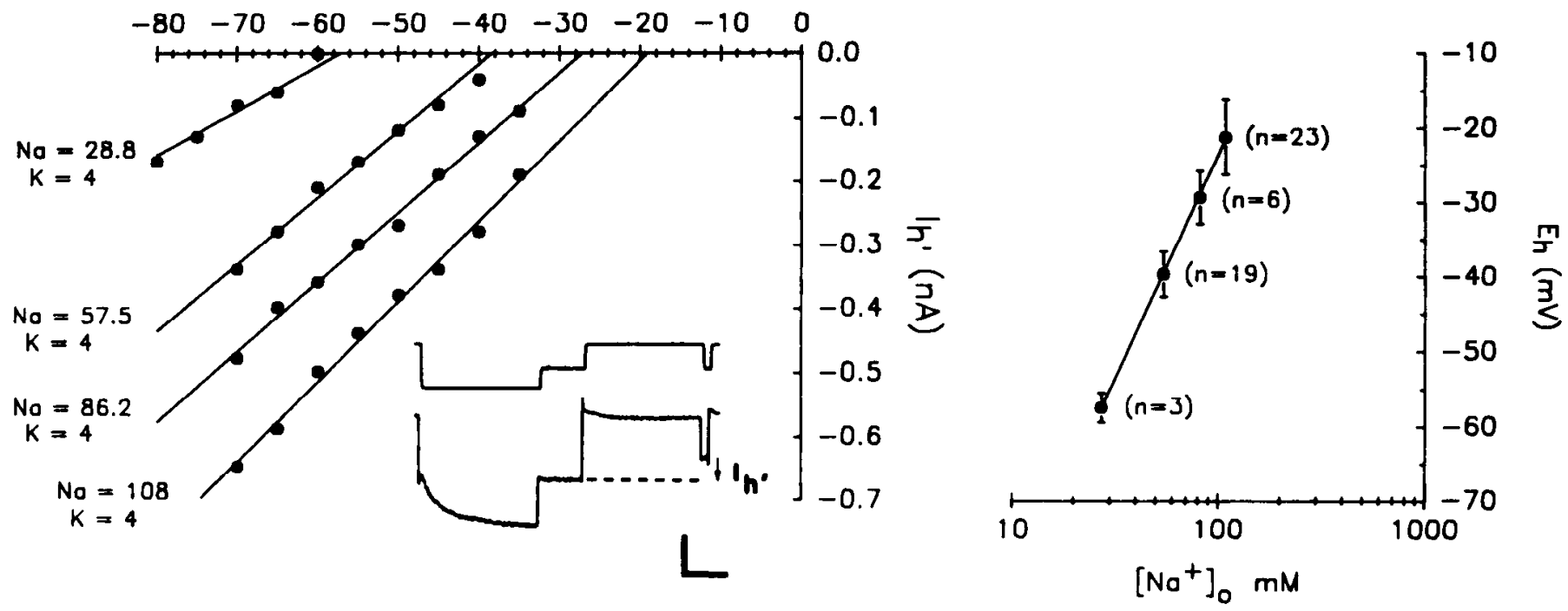

B1.
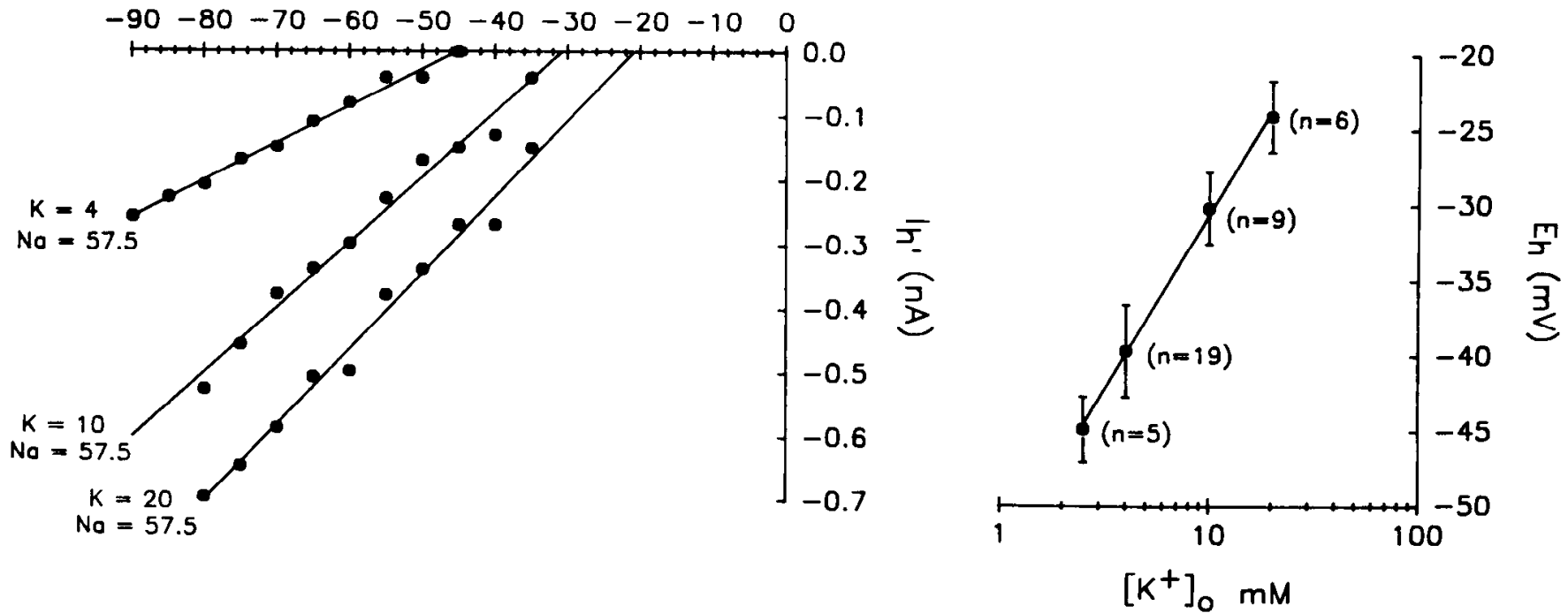

Figure 5. Effect of altering extracellular sodium or potassium on the reversal potential of $I_{h} . A 1$, Graph showing maximally activated $I_{h}\left(I_{\mathrm{h}}\right)$ versus membrane potential in an $\mathrm{HN}(\mathrm{R}, 4)$ cell at 4 concentrations of extracellular $\mathrm{Na}^{+}$. All salines contained $5 \mathrm{mM} \mathrm{Mn}^{2+}, 0.1 \mathrm{mM} \mathrm{Ca}{ }^{2+}$, and $4 \mathrm{mM} \mathrm{K}{ }^{+}$. Solid line was fit to the data points by linear regression. The regression lines extrapolated to zero current intersect the voltage axis at $E_{h}$, the $I_{h}$ reversal potential. In control saline $\left(\left[\mathrm{Na}^{+}\right]_{\mathrm{o}}=108 \mathrm{mM}\right)$, the line extrapolates to a reversal potential of $-19 \mathrm{mV}$. Reductions of $\left[\mathrm{Na}^{+}\right]_{\circ}$ decrease $I_{\mathrm{h}^{\prime}}$, at corresponding potentials and result in parallel shifts of the $I / V$ curve along the voltage axis. Inset, Current record illustrating the method used to measure $I_{h}$ (see text for more details). Holding potential was $-30 \mathrm{mV}$. Scale bar: $80 \mathrm{mV}, 1.2 \mathrm{nA}$, and 1.5 sec. $A 2$, Semilog plot summarizing the reversal potentials of $I_{h}$ measured at 4 different $\left[\mathrm{Na}^{+}\right]_{\mathrm{o}}$. Each point represents the mean $\pm \mathrm{SD}$ of several preparations (indicated in parentheses). The solid line through the points was fit by linear regression and shows that $E_{h}$ varies linearly with the $\log \left[\mathrm{Na}^{+}\right]_{0} . B 1$, Graph showing maximally activated $I_{h}\left(I_{\mathrm{h}}\right)$ versus membrane potential in an $\mathrm{HN}(\mathrm{L}, 7)$ cell at 3 concentrations of extracellular $\mathrm{K}^{+}$. All salines contain $5 \mathrm{mM} \mathrm{Mn}^{2+}, 0.1 \mathrm{mM}^{2}$ $\mathrm{Ca}^{2+}$, and $57.5 \mathrm{mM} \mathrm{Na}{ }^{+}\left(50 \%\right.$ normal). B2, Semilog plot summarizing the dependence of $E_{h}$ on $\left[\mathrm{K}^{+}\right]_{0}$. Normal $\left[\mathrm{K}^{+}\right]_{0}$ is $4 \mathrm{mM}$. Each point represents the mean $\pm \mathrm{SD}$ of several preparations (indicated in parentheses). The solid line through the points was fit by linear regression and shows that $E_{h}$ varies linearly with the $\log \left[\mathrm{K}^{+}\right]_{0}$.

\section{Pharmacology of $\mathrm{I}_{\mathrm{h}}$}

Arbas and Calabrese (1987a) demonstrated that the sag voltage produced by hyperpolarizing currents was blocked in the presence of $5 \mathrm{~mm}$ extracellular $\mathrm{Cs}^{+}$(see also Fig. 11). In voltage clamp, a corresponding block of $I_{h}$ was observed with concen- trations of $\mathrm{Cs}^{+}$as low as $1 \mathrm{~mm}$ (Fig. 8). At lower concentrations of $\mathrm{Cs}^{+}(100-200 \mu \mathrm{M})$, block of $I_{h}$ is incomplete and exhibits strong voltage dependence (Fig. 9). At these concentrations, $\mathrm{Cs}^{+}$ had no effect on the activation threshold or magnitude of $I_{h}$ during small hyperpolarizing steps. However, with larger hyperpolarizations, block of $I_{h}$ became increasingly effective. 

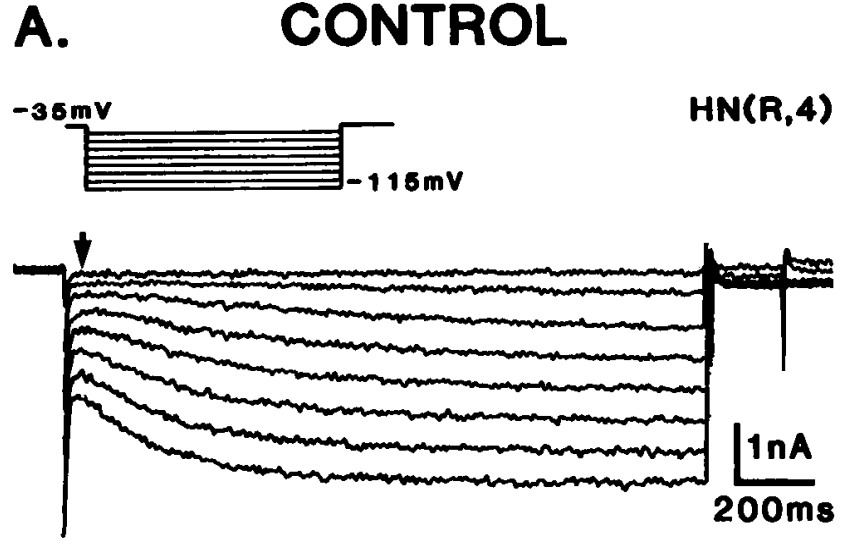

B.

\section{$\mathrm{O} \mathrm{Na}$}
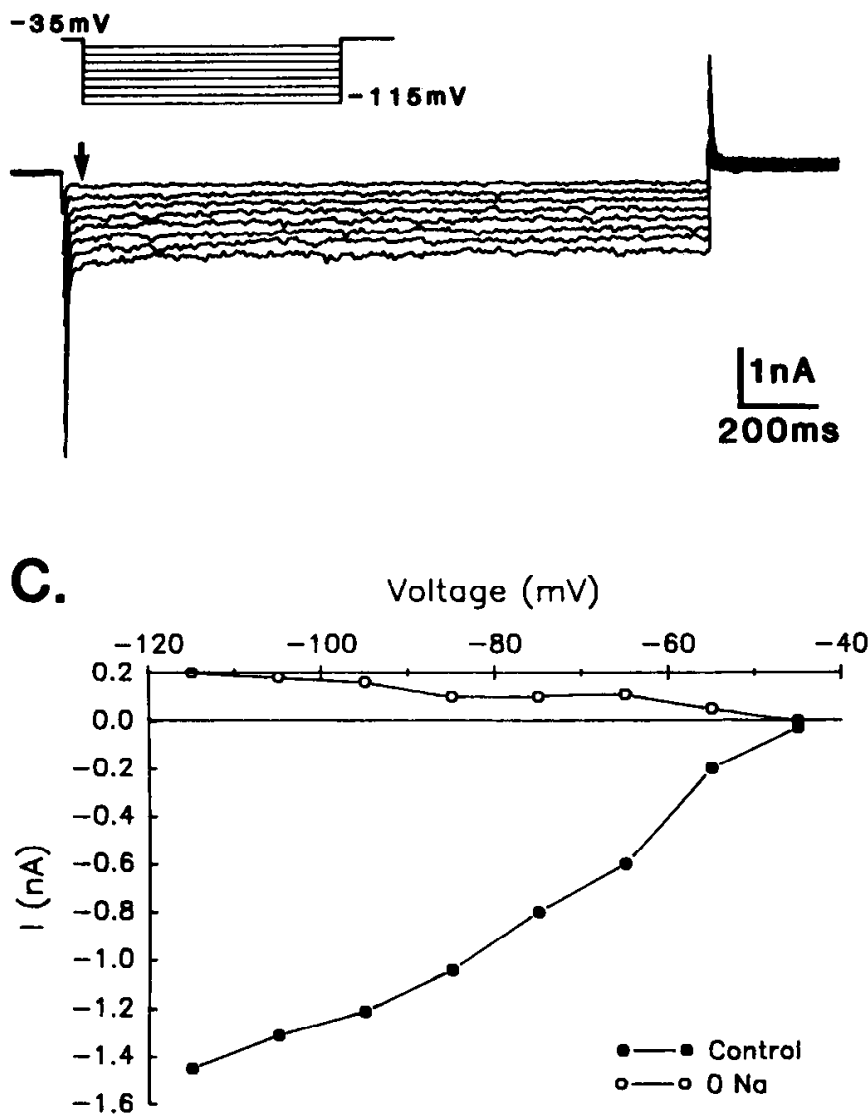

Figure 6. Block of $I_{h}$ in Na-free saline. $A$, Inward currents obtained in an $\mathrm{HN}(\mathbf{R}, 4)$ cell with $1.6 \mathrm{sec}$ hyperpolarizing commands from a holding potential of $-35 \mathrm{mV}$. Inset, The voltage protocol. $B$, Currents recorded after changing to $\mathrm{Na}$-free saline (Tris substituted for $\mathrm{Na}^{+}$). Time-dependent inward currents are eliminated in Na-free saline. $C$, Graph showing time-dependent current measured in control (closed circles) and Na-free saline (open circles). Currents in $A$ and $B$ were measured from a point indicated by the arrow to the end of the voltage step. Both control and $\mathrm{Na}$-free salines contain normal $\mathrm{K}^{+}(4 \mathrm{~mm})$, reduced $\mathrm{Ca}^{2+}(0.1 \mathrm{mM})$, and $5 \mathrm{~mm} \mathrm{Mn}{ }^{2+}$.

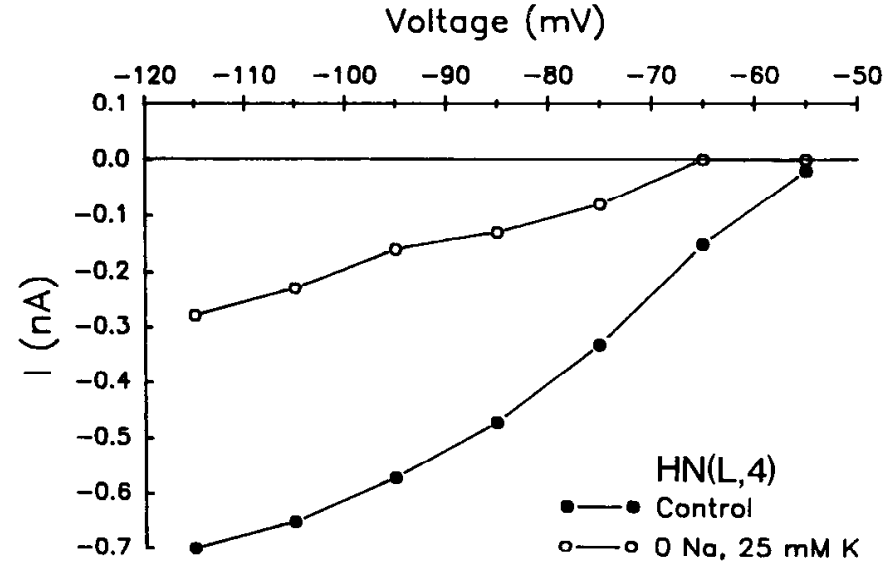

Figure 7. Graph showing the time-dependent current measured in control (closed circles) and $\mathrm{Na}$-free saline containing elevated $\left[\mathrm{K}^{+}\right]_{0}$ (open circles). Holding potential was $-45 \mathrm{mV}$. Voltage steps were $1.6 \mathrm{sec}$ in duration. $\mathrm{Na}^{+}$was replaced with $N$-methyl-D-glucamine. Currents were measured over a region identical to that shown in Figure 6 . Both control and $\mathrm{Na}$-free salines contained reduced $\mathrm{Ca}^{2+}(0.1 \mathrm{~mm})$ and $5 \mathrm{mM} \mathrm{Mn}{ }^{2+}$

Extracellular $\mathrm{Rb}^{+}(1 \mathrm{~mm})$ provided a much less effective block than an equal concentration of $\mathrm{Cs}^{+}(n=3) . I_{h}$ appeared unaffected by $5 \mathrm{~mm}$ extracellular $\mathrm{Ba}^{2+}(n=6)$ or $25 \mathrm{mM}$ extracellular TEA $(n=3)$. Recording with TEA-Cl or TEA-acetate microelectrodes, on the other hand, strongly suppressed $I_{h}(n=5$; data not shown).

\section{Effect of temperature changes on $\mathrm{I}_{\mathrm{h}}$}

Cycling of the heartbeat CPG is strongly affected by changes in temperature, with increasing temperature leading to acceleration. Burst frequency of the heartbeat oscillator exhibits a $Q_{10}$ of approximately 2.4 in the temperature range of $5-26^{\circ} \mathrm{C}$ (Arbas and Calabrese, 1984). Temperature changes also have pronounced and reproducible effects on $I_{h}$. Figure $10 A$ shows the effect of cooling the superfusate from the control value of 25 to $20^{\circ} \mathrm{C}$. Both the rate of activation and the steady-state amplitude of $I_{h}$ were reduced at the lower temperature. In contrast, warming resulted in faster activation and larger steady-state amplitudes of $I_{h}$ (Fig. 10B). The relationship between temperature and steady-state $I_{h}$ for steps to $-90 \mathrm{mV}$ obtained in several preparations is shown in Figure 10C. An approximately linear relationship between $I_{h}$ amplitude and temperature occurs in the temperature range examined. Based on the regression line shown, we estimate a $Q_{10}$ of 2.0 for the effect of temperature on $I_{h}$ amplitude. Figure $10 D$ shows the effect of temperature changes on the activation time constant. Although $\tau_{h}$ varies widely among different preparations, for any given cell, temperatures increases (filled circles) consistently decrease $\tau_{h}$, while temperature decreases (open circles) increase $\tau_{h}$. We estimate a $Q_{10}$ of approximately 2.4 for the effect of tempcraturc on $\tau_{h}$. Thesc data indicate that changes in body temperature occurring in the wild could have substantial effects on the amplitude and kinetics of $I_{h}$.

\section{Insensitivity of $\mathrm{I}_{\mathrm{h}}$ to serotonin and FMRFamide}

The heartbeat oscillator is accelerated by low concentrations $\left(10^{-9}-10^{-6} \mathrm{M}\right)$ of serotonin (Arbas and Norris, unpublished data) or the peptide FMRFamide (Kuhlman et al., 1985). These effects 
A. CONTROL

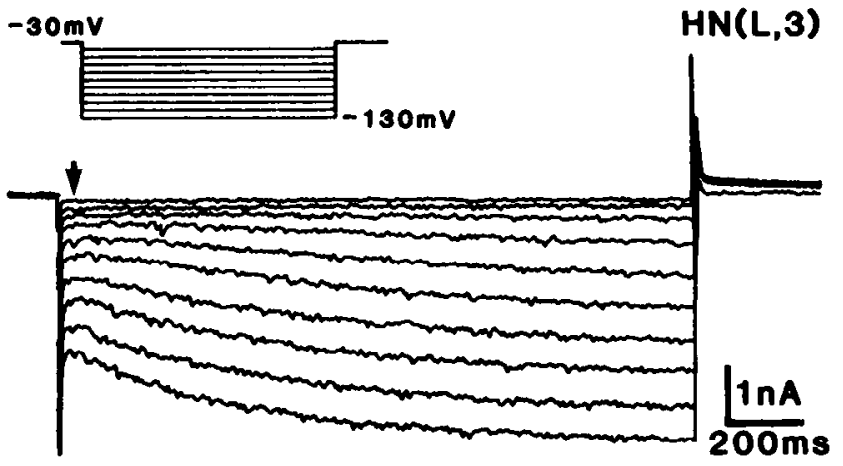

B.

$1 \mathrm{mM}$ Cs
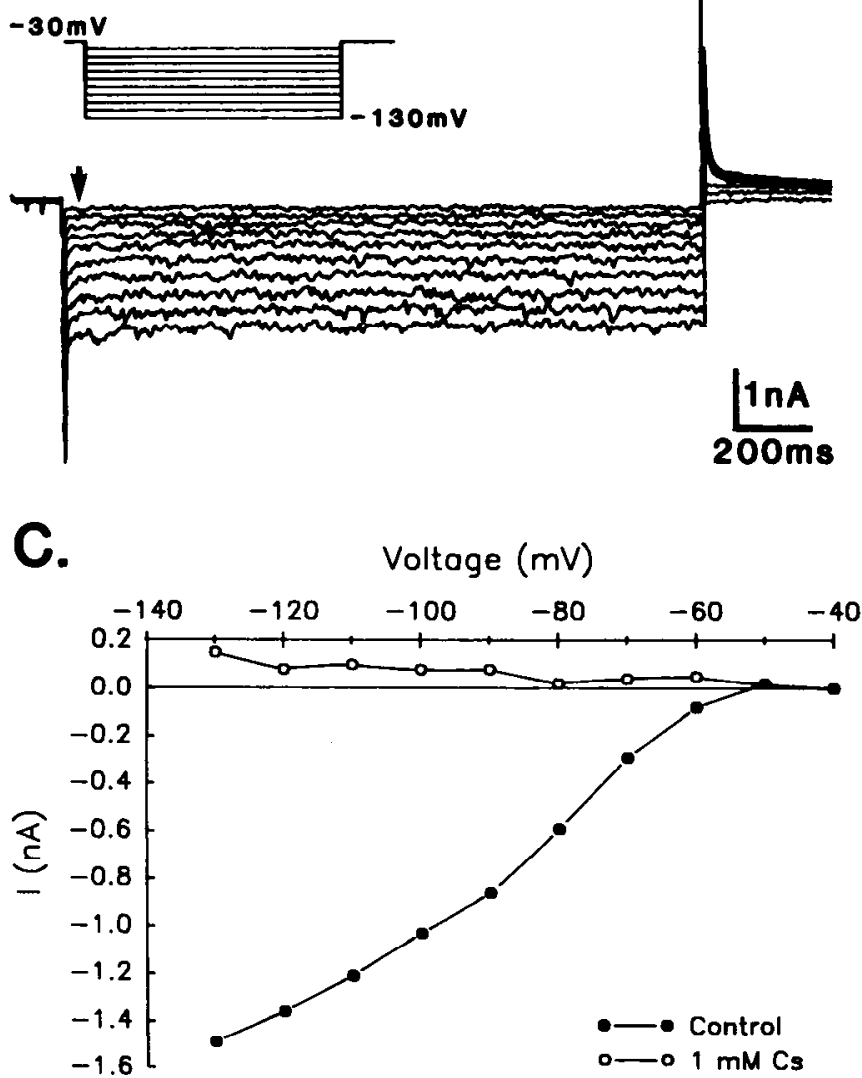

Figure 8. Block of $I_{h}$ by extracellular cesium. $A$, Inward currents obtained in an $\mathrm{HN}(\mathrm{L}, 3)$ cell with $1.6 \mathrm{sec}$ hyperpolarizing commands from a holding potential of $-30 \mathrm{mV}$. Ganglion bathed in $5 \mathrm{~mm} \mathrm{Mn}^{2+}$ saline. Inset, The voltage protocol. $B$, Currents recorded after the addition of $1 \mathrm{mM} \mathrm{Cs}^{+}$to the saline. $C$, Graph showing time-dependent current measured in control (closed circles) and in the presence of $\mathrm{Cs}^{+}$(open circles). Currents in $A$ and $B$ were measured from a point indicated by the arrow to the end of the voltage step.

do not appear to be mediated via modulation of $I_{h}$, however. Bath application of $10^{-6} \mathrm{M} 5$-HT $(n=3)$ or $10^{-6} \mathrm{M}$ FMRFamide $(n=10)$ failed to reveal any changes in the voltage sensitivity, kinetics, or steady-state amplitude of $I_{h}$ (data not shown).

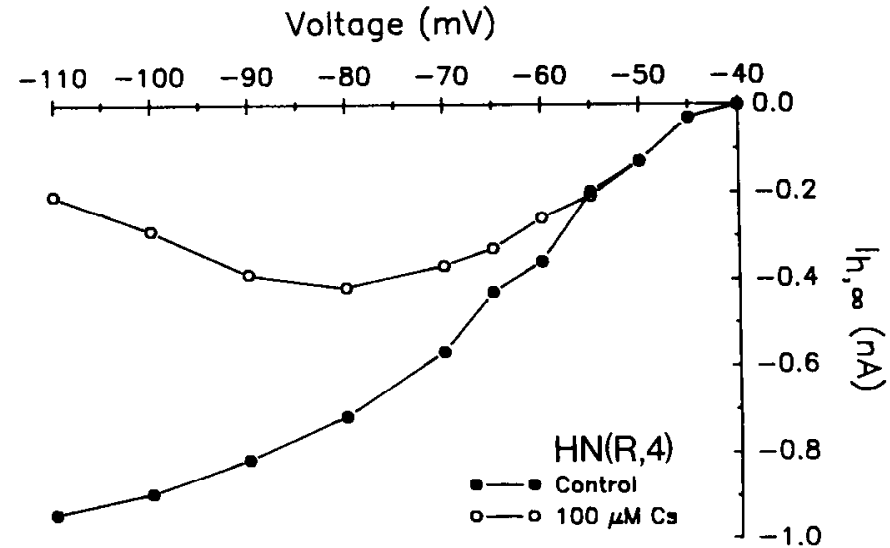

Figure 9. Voltage dependence of $\mathrm{Cs}^{+}$block. Closed circles show timedependent $I_{h}$ measured in $\mathrm{Mn}^{2+}$ saline at the end of $6 \mathrm{sec}$ hyperpolarizing voltage steps. Open circles show time-dependent $I_{h}$ measured after addition of $100 \mu \mathrm{M} \mathrm{Cs}{ }^{+}$to the saline. The block becomes increasingly effective at more hyperpolarized potentials.

\section{Effect of $\mathbf{I}_{\mathrm{h}}$ block on the oscillatory activity of $H N$ cells in isolated ganglia}

Timing of leech heartbeat is controlled by a subset of the HN cell network (the timing oscillator) consisting of the $8 \mathrm{HN}$ cells in ganglia 1-4 (see review by Calabrese and Peterson, 1983). Current-clamp studies of HN cells in isolated ganglia 3 or 4 suggested that phase transitions within the timing oscillator depended on an endogenous property of the HN cells (Peterson, 1983). The voltage "sag" occurring in response to injection of hyperpolarizing currents was proposed to provide such a mechanism (Arbas and Calabrese, 1987a). According to this hypothesis, hyperpolarizing inputs consisting of summed IPSPs from presynaptic $\mathrm{HN}$ cells activate the sag voltage response, resulting in a slow recovery to the threshold for burst generation. If the sag voltage response is, in fact, the primary mechanism responsible for the recovery from inhibition of $\mathrm{HN}$ cells, then elimination of the sag voltage response should disrupt the normal bursting behavior of the timing oscillator. We tested this hypothesis by blocking $I_{h}$, which underlies the sag voltage response, with bath application of $\mathrm{Cs}^{+}(2-4 \mathrm{~mm})$.

The preparations consisted of an isolated ganglion 3 or 4 , each of which contains a bilateral pair of $\mathrm{HN}$ cells connected by reciprocally inhibitory chemical synapses. Figure 11 illustrates the effects of extracellular $\mathrm{Cs}^{+}$on one of these preparations. Figure $11 \mathrm{Al}$ illustrates the typical oscillatory activity of $\mathrm{HN}$ cell pairs in normal leech saline, which consists of alternating bursts of spikes. The antiphasic relationship of the bursts is assured by the reciprocally inhibitory interaction between the HN cells, mediated by both spiking and nonspiking chemical synaptic transmission (Peterson, 1983; Arbas and Calabrese, 1987b). Figure $11 A 2$ shows the sag voltage produced by a prolonged hyperpolarizing current pulse injected into one of the $\mathrm{HN}$ cells. In Figure $11 B 1,4 \mathrm{mM} \mathrm{Cs}^{+}$has been added to the superfusate, resulting in a disruption of normal bursting activity. In general, the $\mathrm{HN}$ cells fire tonically in the presence of $\mathrm{Cs}^{+}$, although sporadic alternate bursting cycles are sometimes observed (not shown). Figure $11 B 2$ shows the elimination of the sag voltage response, and thus block of $I_{h}$, in the presence of $\mathrm{Cs}^{+}$. Note that the plateau potential following the hyperpolarizing step persists in $\mathrm{Cs}^{+}$saline and that synaptic transmission remains strong. 
A. COOLING

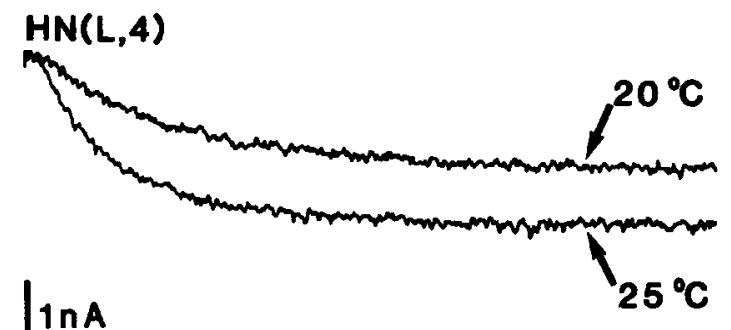

$300 \mathrm{~ms}$

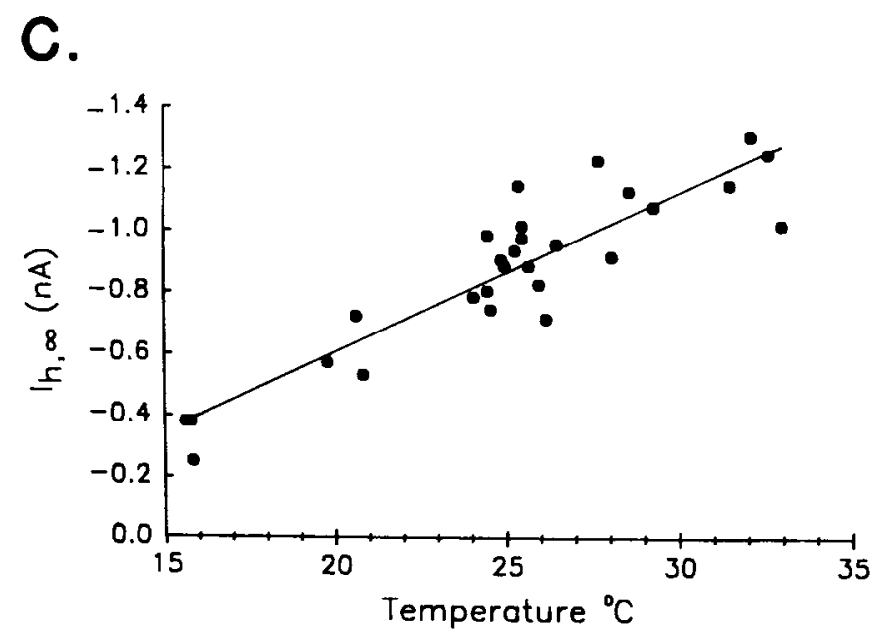

B. WARMING
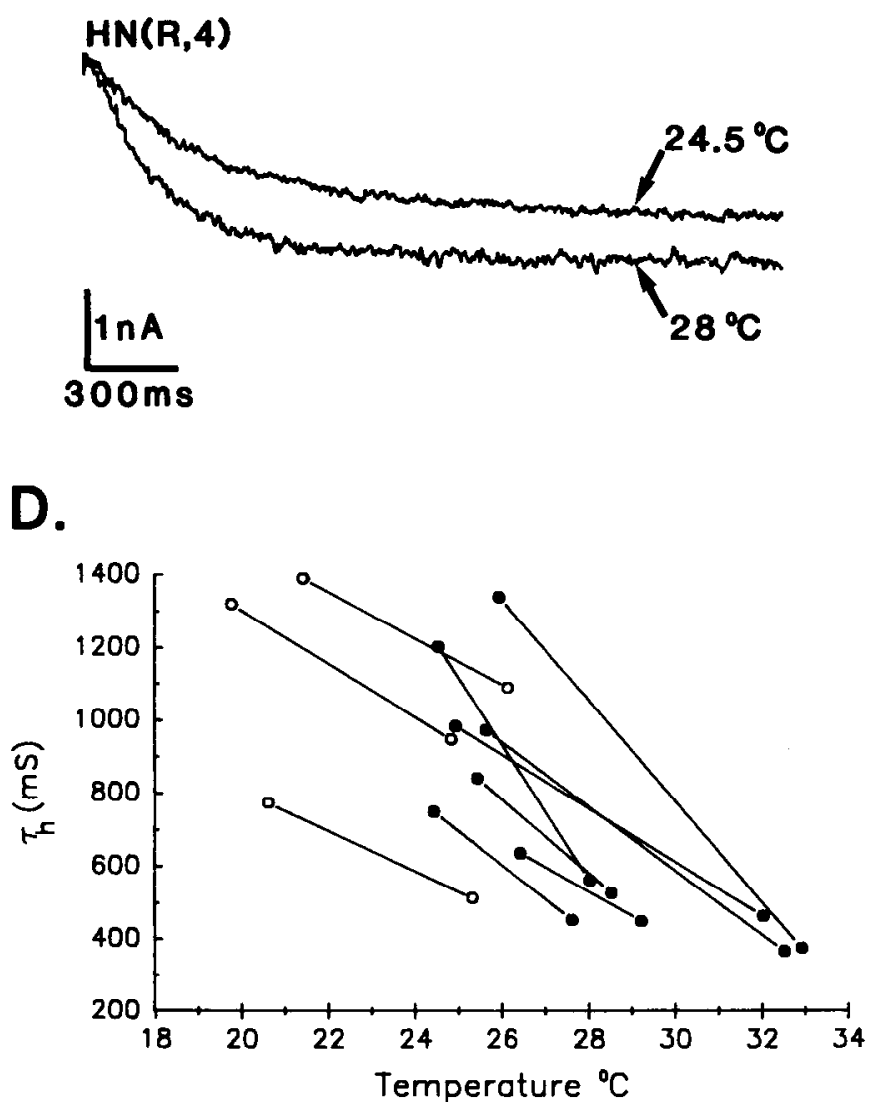

Figure 10. Effect of temperature on $I_{\mathrm{h}} . A$, Inward currents recorded in an $\mathrm{HN}(\mathrm{L}, 4)$ cell during a voltage step from the holding potential of -30 $\mathrm{mV}$ to a command potential of $-90 \mathrm{mV}$. Cooling results in a decreased steady-state amplitude and slower rate of activation of $I_{h}$. $B$, Inward currents recorded in an $\mathrm{HN}(\mathrm{R}, 4)$ cell using the same voltage protocol as in $A$. Warming results in an increased steady-state amplitude and faster rate of activation of $I_{h}$. C, Graph illustrating the relationship between temperature and steady-state amplitude of $I_{n}$ during voltage steps to - 90 $\mathrm{mV}$ in several preparations $(n=14)$. Each point represents steady-state $I_{h}$ measured during a voltage step to $-90 \mathrm{mV}$. The solid line through the data points was fit by linear regression. $D$, Graph showing the relationship between temperature and the activation time constant $\left(\tau_{h}\right)$ of $I_{h}$ during voltage steps to $-90 \mathrm{mV}$. The solid lines connect data points at the control and test temperatures obtained from 10 different preparations. Filled circles represent warming experiments and open circles cooling experiments.

Based on preliminary voltage-clamp experiments, the concentration of $\mathrm{Cs}^{+}$used in these experiments is unlikely to suppress voltage-sensitive outward currents. This conclusion is supported by the observation that action potential durations were unaffected during $\mathrm{Cs}^{+}$application (data not shown). Figure $11 \mathrm{Cl}$ and $11 C 2$ show bursting activity and the sag voltage response after washing with normal saline. Similar disruptions of normal oscillatory activity were obtained in 8 additional preparations tested. These data are consistent with the hypothesis that $I_{h}$ contributes to the recovery from inhibitory inputs by individual HN cells and suggests that $I_{h}$ may be required for the maintenance of normal bursting behavior in isolated ganglia.

\section{Discussion}

The properties of the hyperpolarization-activated current $I_{h}$ presented here appear to account for all of the previously described characteristics of the sag voltage response of $\mathrm{HN}$ cells in current clamp (Arbas and Calabrese, 1987a). Specifically, $I_{h}$ and the sag voltage response share the following features: (1) activation threshold near $-50 \mathrm{mV}$, (2) association with a conductance increase, (3) slow kinetics, (4) no inactivation, (5) persistence in
$\mathrm{Mn}^{2+}$ or $\mathrm{Co}^{2+}$ salines, (6) dependence on extracellular $\mathrm{Na}^{+}$, and (7) block by external $\mathrm{Cs}^{+}$. The previous observation that the sag response disappears at holding potentials negative to $-70 \mathrm{mV}$ (see Fig. 8 of Arbas and Calabrese, 1987a) can also be explained. Plots of the steady-state activation of $I_{h}$ versus voltage show that the conductance becomes fully activated between -70 and $-80 \mathrm{mV}$. Thus, current steps applied at hyperpolarized holding potentials will produce no additional activation of the conductance and thus fail to generate additional time-dependent current. Thus, a single current, $I_{h}$, can account for all of the reported properties of the sag voltage response.

\section{Comparisons to similar currents in other preparations}

Ionic currents similar to $I_{h}$ have been reported in a diverse group of cell types, including mammalian heart muscle (Brown and DiFrancesco, 1980; DiFrancesco, 1985), salamander photoreceptors (Bader and Bertrand, 1984), mouse dorsal root ganglion cells (Mayer and Westbrook, 1983), pyramidal cells in the guinea pig hippocampus (Halliwell and Adams, 1982), and stretch receptor neurons in the lobster (Edman et al., 1987). In all these cases, the current is produced by a mixed $\mathrm{Na}^{+} / \mathrm{K}^{+}$conductance 
A1. NORMAL SALINE
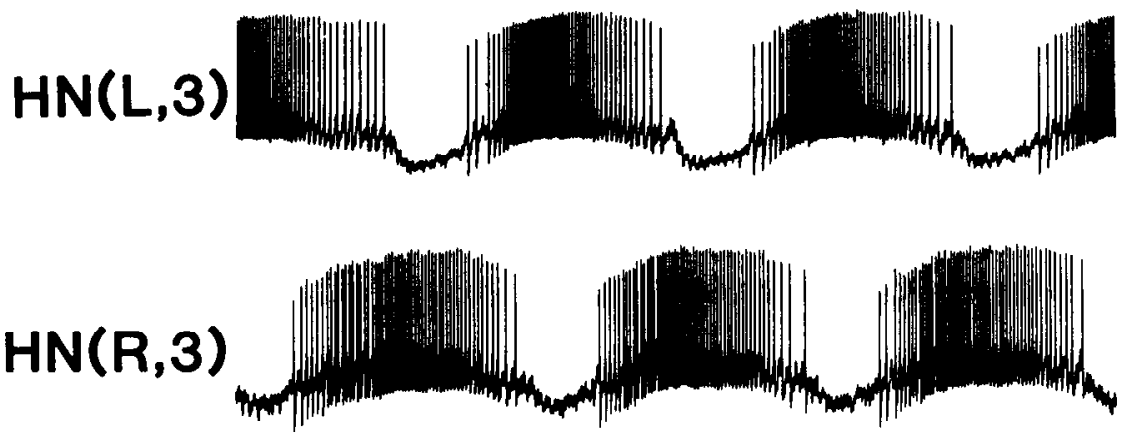

B1.

$4 \mathrm{mM}$ Cs
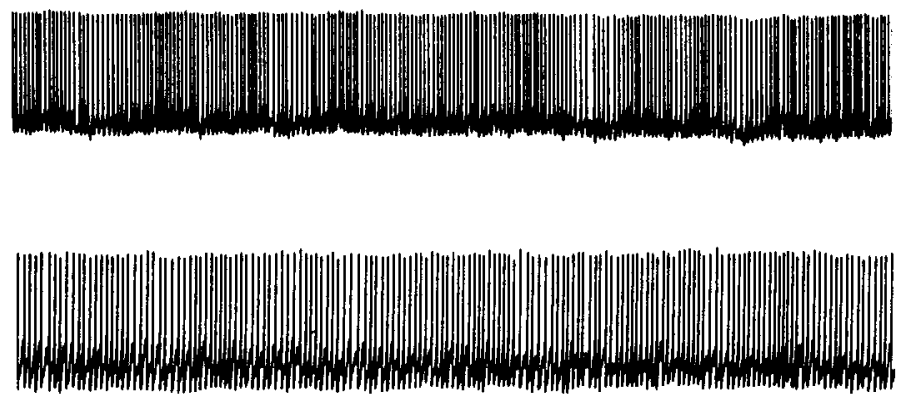

C1. NORMAL SALINE

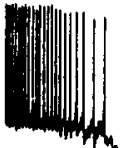

$30 \mathrm{mV}$

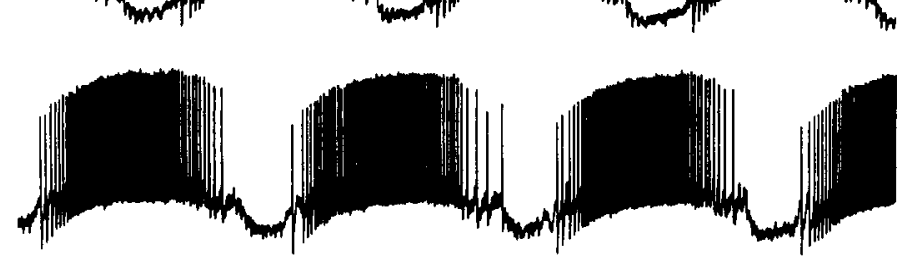

A2.
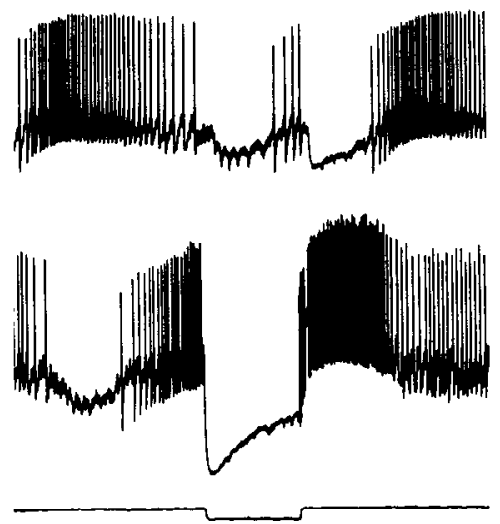

B2.
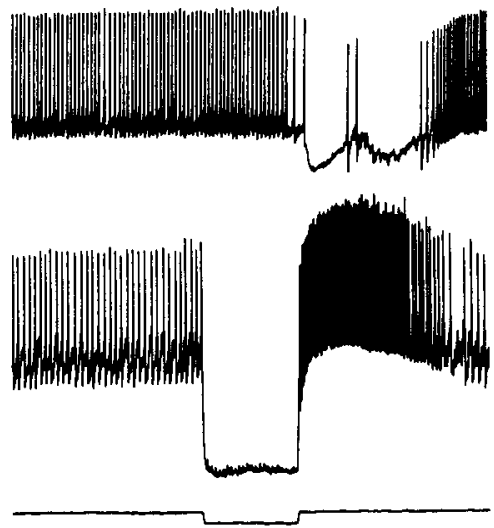

C2.
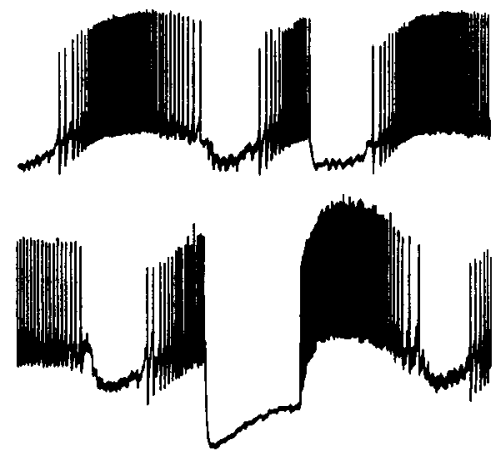

$2.5 n A$

$3 \sec$

Figure 11. Effect of $\mathrm{Cs}^{+}$on oscillatory activity in the bilateral pair of $\mathrm{HN}$ cells in ganglion 3. Panels on left illustrate spontaneous activity; panels on right show the voltage response, recorded in $\mathrm{DCC}$, of the $\mathrm{HN}(\mathrm{R}, 3)$ cell to a prolonged hyperpolarizing current pulse. Lower trace in each panel is a current monitor. $A$, Spontaneous activity in normal leech saline consists of alternating bursts in the HN cells. The hyperpolarizing current pulse elicits a sag voltage response in the $H N(R, 3)$ cell. The presence of the sag voltage response serves as a reliable indicator of $I_{h}$ activation without entering voltage-clamp mode. $B$. Normal rhythmic activity is blocked after addition of $4 \mathrm{mM} \mathrm{Cs}^{+}$. Injection of the hyperpolarizing current pulse demonstrates the complete block of the sag voltage response. $C$, Normal rhythmic activity and sag voltage response after washing with normal saline.

with a reversal potential near -20 to $-30 \mathrm{mV}$ and an activation threshold near $-50 \mathrm{mV}$ (an exception is Iq in guinea pig hippocampus, which has a threshold near $-80 \mathrm{mV}$ and a reversal potential of -50 to $-60 \mathrm{mV}$ ). Other similarities include the relatively slow activation kinetics, lack of inactivation, and voltage-dependent block by extracellular $\mathrm{Cs}^{+}$.

The elimination of $I_{h}$ in Na-free saline reported here was not unexpected given the previously described $\mathrm{Na}$ dependence of 
the sag voltage response in current clamp (Arbas and Calabrese, 1987a). On the other hand, since $\mathrm{K}^{+}$ions presumably remain available to carry current in $\mathrm{Na}$-free saline, one would expect at least some fraction of $I_{h}$ to persist and to generate timedependent inward current during voltage steps to levels more negative than the potassium equilibrium potential. In fact, the only time-dependent currents observed in Na-free saline (with normal extracellular $\mathrm{K}^{+}$) were small and outwardly rectifying (see Fig. 6C). [The source of these residual outward currents is not yet clear. They appear not to represent an artifact of $\mathrm{Na}$ free saline itself, since similar currents are observed when $I_{h}$ is blocked with $\mathrm{Cs}^{+}$(see Fig. 8C). The currents could represent deactivation of a voltage-sensitive K-current or an as yet unidentified nonspecific current, some fraction of which continues to flow at the holding potential. The observation that the outwardly rectifying currents tend to increase with larger hyperpolarizations is consistent with this interpretation.]

The elimination of $I_{h}$ in Na-free saline is also unlikely to be an indirect effect of the substituted cation since it occurs when either Tris or $N$-methyl-D-glucamine replaces $\mathrm{Na}^{+}$. It is possible that some fraction of $I_{h}$ does remain in $\mathrm{Na}$-free saline (containing normal extracellular $\mathrm{K}^{+}$) but is negligible in the voltage range examined. This hypothesis is supported by the observation that time-dependent inward currents are readily measured in $\mathrm{Na}$ free saline with elevated $\mathrm{K}^{+}$(cf. Fig. 7). By shifting $E_{K}$ toward more depolarized potentials, high-K $\mathrm{K}^{+}$saline would be expected to extend the voltage range over which $I_{h}$ activation would generate inward current flow in Na-free saline. In addition, the driving force for $\mathrm{K}^{+}$entry into the cell at any given membrane potential (negative to $E_{K}$ ) would be increased compared with the driving force at the lower $\mathrm{K}^{+}$concentration.

Another possibility, however, is that $\mathrm{Na}^{+}$ions interact with the channel itself and that some minimum concentration of $\mathrm{Na}^{+}$ (in normal extracellular $\mathrm{K}^{+}$) may be required for the channel to function properly. We have already noted the effects of elevated $\mathrm{K}^{+}$on the fully activated $I / V$ curves for $I_{h}$ (see Fig. $5 B$ ). DiFrancesco (1982) attributed similar effects of $\mathrm{K}^{+}$on the current $I_{f}$ of calf Purkinje fibers to a $\mathrm{K}^{+}$-mediated channel activation process. Thus, it is possible that both $\mathrm{K}^{+}$and $\mathrm{Na}^{+}$ions influence the gating of the ion channels underlying $I_{h}$ in leech HN cells. Further studies will be required to resolve this issue.

\section{Effects of temperature on $\mathrm{I}_{\mathrm{h}}$}

The heartbeat central pattern generator is accelerated by increasing temperatures and slowed by decreasing temperatures (Arbas and Calabrese, 1984). The modulatory effects of temperature on $I_{h}$ described in this study are consistent with these effects. For example, the increased rate of activation and steadystate amplitude of $I_{h}$ produced by a temperature increase would be expected to increase the rate of recovery of $\mathrm{HN}$ cells from inhibitory inputs. A faster recovery would decrease the interburst period of the HN cells and could, in turn, lead to acceleration of rhythmic activity in the entire network. It is interesting to note that the $Q_{10}$ values estimated for $I_{h}$ amplitude $\left(Q_{10}\right.$ $=2.0)$ and activation kinetics $\left(Q_{10}=2.4\right)$ are similar to the mean $Q_{10}$ value obtained for the beat frequency of the heartbeat oscillator as a whole $\left(Q_{10}=2.4\right)$ (Arbas and Calabrese, 1984).

\section{Functional role of $\mathrm{I}_{\mathrm{h}}$ : Recovery from synaptic inhibition?}

The normal electrical activity of $\mathrm{HN}$ cells consists of rhythmic bursts of action potentials separated by barrages of IPSPs (see Fig. 11A). In an isolated ganglion 3 or 4 , these IPSPs arise principally from the contralateral HN cell but also from the axon stumps of ipsilateral HN cells projecting from more anterior ganglia (Peterson, 1983). Under normal circumstances, bursts are terminated when the contralateral $\mathrm{HN}$ cell begins to fire. Recovery from inhibition, on the other hand, appears to occur in the face of continuing inhibitory input and has therefore been attributed to an intrinsic property of the HN cells (Peterson, 1983).

The hyperpolarization-activated $I_{h}$, which underlies the sag voltage response described by Arbas and Calabrese (1987a), appears to provide an intrinsic mechanism for recovery from inhibition. $I_{h}$ is clearly activated at membrane potentials reached during the inhibitory phase of $\mathrm{HN}$ cell oscillations (approximately $-60 \mathrm{mV}$ ). In addition, since $I_{h}$ does not inactivate, the current would continue to oppose further hyperpolarization of the cell as long as the membrane potential remained below its activation threshold $(-50 \mathrm{mV})$. Finally, the delays to onset and slow kinetics of $I_{h}$, which are most pronounced at the same membrane potentials to which HN cells are hyperpolarized during normal oscillatory activity, may serve to ensure that recovery to threshold for the succeeding burst does not occur too rapidly. The observation that occasional burst cycles can occur under conditions where $I_{h}$ is totally suppressed suggests that other factors, such as synaptic fatiguc and activation of Camediated plateau potentials, may also play a role in the recovery of HN cells from inhibition (perhaps acting in parallel with $I_{h}$ ). Nevertheless, the demonstration that block of $I_{h}$ disrupts the normal burst pattern of $\mathrm{HN}$ cells in isolated ganglia is consistent with the hypothesis that activation of $I_{h}$ aids in recovery from inhibition leading to subsequent burst initiation and plays a critical role in the maintenance of oscillatory activity between HN cell pairs.

\section{References}

Arbas, E. A., and R. L. Calabrese (1984) Rate modification in the heartbeat central pattern generator of the medicinal leech. J. Comp. Physiol. 155: 783-794.

Arbas, E. A., and R. L. Calabrese (1987a) Ionic conductances underlying the activity of interneurons that control heartbeat in the medicinal leech. J. Neurosci. 7: 3945-3952.

Arbas, E. A., and R. L. Calabrese (1987b) Slow oscillations of membrane potential in interneurons that control heartbeat in the medicinal leech. J. Neurosci. 7: 3953-3960.

Bader, C. R., and D. Bertrand (1984) Effect of changes in intra- and extracellular sodium on the inward (anomalous) rectification in salamander photoreceptors. J. Physiol. (Lond.) 347: 611-631.

Brown, H., and D. DiFrancesco (1980) Voltage-clamp investigations of membrane currents underlying pace-maker activity in rabbit sinoatrial node. J. Physiol. (Lond.) 308: 331-351.

Calabrese, R. L. (1977) The neural control of alternate heartbeat coordination states in the leech, Hirudo medicinalis. J. Comp. Physiol. 122: 111-143.

Calabrese, R. L., and E. Peterson (1983) Neural control of heartbeat in the leech, Hirudo medicinalis. Symp. Soc. Exp. Biol. Med. 37: 195221.

DiFrancesco, D. (1981) A new interpretation of the pace-maker current in calf Purkinje fibers. J. Physiol. (Lond.) 314: 359-376.

DiFrancesco, D. (1982) Block and activation of the pacemakcr channel in calf Purkinje fibres: Effects of potassium, caesium, and rubidium. J. Physiol. (Lond.) 329: 485-507.

DiFrancesco, D. (1985) The cardiac hyperpolarizing-activated current,

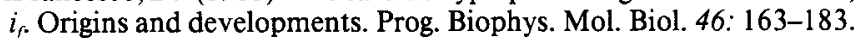

Edman, A., S. Gestrelius, and W. Grampp (1987) Current activation by membrane hyperpolarization in the slowly adapting lobster stretch receptor neurone. J. Physiol. (Lond.) 384: 671-690.

Halliwell, J. V., and P. R. Adams (1982) Voltage-clamp analysis of muscarinic excitation in hippocampal neurons. Brain Res. 250: 7192. 
Hestrin, S. (1987) The properties and function of inward rectification in rod photoreceptors of the tiger salamander. J. Physiol. (Lond.) 390: 319-333.

Kuhlman, J. R., C. Li, and R. L. Calabrese (1985) FMRF-amide-like substances in the leech. II. Bioactivity on the heartbeat system. J. Neurosci. 5: 2310-2317.

Mayer, M. L., and G. L. Westbrook (1983) A voltage-clamp analysis of inward (anomalous) rectification in mouse spinal sensory ganglion ncurones. J. Physiol. (Lond.) 340: 19-45.

Nicholls, J. G., and D. A. Baylor (1968) Specific modalities and receptive fields of sensory neurons in the CNS of the leech. J. Neurophysiol. 31: 740-756.

Peterson, E. L. (1983) Generation and coordination of heartbeat tim- ing oscillation in the medicinal leech. I. Oscillation in isolated ganglia. J. Neurophysiol. 49:611-626.

Peterson, E. L., and R. L. Calabrese (1982) Dynamic analysis of a rhythmic neural circuit in the leech, Hirudo medicinalis. J. Neurophysiol. 47: 256-271.

Thompson, W. J., and G. S. Stent (1976) Neuronal control of heartbeat in the medicinal leech. II. Intersegmental coordination of heart motor neuron activity by heart interneurons. J. Comp. Physiol. 111: 281307.

Tolbert, L. P., and R. L. Calabrese (1985) Anatomical analysis of contacts between identified neurons that control heartbeat in the leech Hirudo medicinalis. Cell Tissue Res. 242: 257-267. 